\title{
Stilbenoids: Chemistry, occurrence, bioavailability and health effects-a review
}

\author{
Won Young Oh, Yue Gao and Fereidoon Shahidi*
}

Department of Biochemistry, Memorial University of Newfoundland, St. John's, NL, Canada A1B 3X9

${ }^{*}$ Corresponding author: Fereidoon Shahidi, Department of Biochemistry, Memorial University of Newfoundland, St. John's, NL, Canada A1B 3X9. Tel: +1 7097378552 E-mail: fshahidi@mun.ca

DOI: $10.31665 /$ JFB.2021.13256

Received: August 01, 2020; Revised received \& accepted: August 31, 2020

Citation: Oh, W.Y., Gao, Y., and Shahidi, F. (2021). Stilbenoids: chemistry, occurrence, bioavailability and health effects-a review. J. Food Bioact. 13: 20-31.

\begin{abstract}
Stilbenoids are synthesized by plants in response to external stimuli such as infection and UV-irradiation, thus known as phytoalexins. Stilbenoids include resveratrol, piceid, piceatannol, pterostilbene, astringin, and viniferin and have been of interest due to their myriad of health benefits, such as antioxidant, anti-inflammatory, anticancer, and anti-diabetic effects. Despite their numerous health effects, the bioavailability of stilbenoids is poor. However, the existing literature on this subject is fragmented and thus collective effort is needed to better understand their role before and after consumption. Therefore, this contribution provides an overview of the synthesis, occurrence, bioavailability and health benefit of stilbenoids.
\end{abstract}

Keywords: Stilbenoid; Occurrence; Bioavailability; Health effect; Resveratrol.

\section{Introduction}

Stilbenes are naturally occurring secondary metabolites, which have an important disease resistance mechanism and are known as phytoalexins (Langcake and Pryce, 1977; Kuć, 1995; Roupe et al., 2006a; Błaszczyk et al., 2019). Stilbenoids, named by Gorham in 1980, are hydroxylated derivatives of stilbenes (Gorham, 1980; Xiao et al., 2008). Stilbenoids consist of two benzene rings joined by an ethylene bridge and belong to one of the categories of phenolic compounds that share their synthesis pathway with flavonoids. So far, more than 1,000 stilbenoids have been identified (Shen et al, 2013) and these include resveratrol, piceid, piceatannol, pterostilbene, astringin, and viniferin. Grapes are the primary food source of stilbenoids (Adrian et al., 2000; Rimando et al., 2004; Viñas et al., 2011; Vrhovsek et al., 2012).

Stilbenoids have been of interest due to their antioxidant (Oh and Shahidi, 2017; Oh et al., 2019; Treml et al., 2019), anti-inflammatory (Leláková et al, 2019; Hošek et al, 2019), anticancer (Cuzick et al., 2015) cardioprotective (Zamora-Ros et al., 2012), anti-Alzheimer's (Moussa et al., 2017), and anti-diabetic (Banaszewska et al., 2016) activities. In addition, resveratrol, for example, has a higher lipophilicity compared to other phenolic compounds, which may lead to its better cell permeability (Neves et al., 2013). Indeed, resveratrol shows better absorption compared to other phenolics (Walle et al., 2004). However, its bioavailability is relatively poor due to its extensive metabolism, thus no correlation exists between in vitro and in vivo results (Walle et al., 2004; Roupe et al., 2006b; Baur and Sinclair, 2006). Therefore, it is also important to understand their absorption and metabolism. This review provides details about the synthesis, occurrence, bioavailability and health benefit of stilbenoids.

\section{Chemistry and biosynthesis}

Stilbenes are C6-C2-C6 compounds consisting of two bezene rings linked by an ethylene bridge (Figure 1). The double bond located between the two benzene rings can either assume $E$ (trans) or $Z$ (cis) configuration. Trans-configuration is the predominant form and it has better antioxidant and anticancer activities (Roupe et al., 2006a). Stilbenoid backbone contains one or more hydroxyl and can also have other substituents such as methyl, methoxy, 
<smiles>C(=C/c1ccccc1)\c1ccccc1</smiles>

Trans form<smiles>C(=C\c1ccccc1)\c1ccccc1</smiles>

Cis form

\section{Health benefit}

Stilbenoids have received much attention in recent years due to their general health benefits as antioxidants and anti-inflammatory agents. In the past ten years, medical researchers have invested much effort into exploring the benefits of stilbenoids on conditions ranging from dry skin to Alzheimer's disease.

\subsection{Antioxidant effect}

prenyl, and/or sugar groups and possibly with different degrees of polymerization (dimer, trimer, etc.) (Shen et al., 2013). Stilbenoids include resveratrol, piceid, pterostilbene, piceatannol, astringin, pinosylvin, and rhapontigenin (Figure 2).

Stilbenoids are derived from phenylpropanoids pathway as shown in Figure 3. The synthesis of stilbenoids starts from phenylalanine by phenylalanine ammonia lyase (PAL) forming carboncarbon double bond (Shahidi and Naczk, 1995). In some cases, tyrosine can replace phenylalanine in this pathway and the enzyme in this process is tyrosine ammonia lyase (TAL). The product, transcinnamic acid, is further processed by monooxygenase (cytochrome $\left.\mathrm{P}_{450}\right)$, yielding $p$-coumaric acid. CoA ligase turns $p$-coumaric acid into $p$-coumaryl CoA and this interacts with 3 molecules of malonyl CoA (Roupe et al., 2006a). The tetraketide formed undergoes aldol reaction by stilbene synthase and forms resveratrol, the best known stilbenoid (Dewick, 2002; Shen et al., 2013).

\section{Occurrence}

Stilbenes are produced in response to stress, injury, infection, or UV-irradiation (Kuć, 1995; Soleas et al., 1997). In addition, the concentration of stilbene is affected by many factors such as cultivar, genotype, soil type, climate, light exposure, pest management, agronomy, ripeness, storage condition, and postharvest treatment (Roupe et al., 2006a; Błaszczyk et al., 2019).

Table 1 shows representative food sources of stilbenoids. Among stilbenoids, resveratrol has been distributed more widely than others. The most abundant dietary source of resveratrol is grape, thus it can also be found in grape products such as wine and grape juice (Rimando et al., 2004; Vitrac et al., 2005; RomeroPérez et al., 1999). Stilbenoids also found in peanut and peanut products. According to Sobolev and Cole (1999), roasted peanuts, peanut butter, and boiled peanuts contained trans-resveratrol at a level of $0.018-0.080,0.148-0.504,0.048$ (liquid)-7.092 (kernel) $\mu \mathrm{g} / \mathrm{g}$, respectively. Ibern-Gómez et al. (2000) also reported similar results in peanut butter products $(0.265-0.753 \mu \mathrm{g} / \mathrm{g})$. In addition, they observed trans-piceid that ranged from 0.067 to $0.225 \mu \mathrm{g} / \mathrm{g}$ in peanut butter products. Hurst et al. (2008) studied the stilbenoids (trans-resveratrol and trans-piceid) contents of cocoa-containing and chocolate products that were correlated with the quantity of non-fat cocoa solid in the products. Ragab et al. (2006) found stilbenoids such as cis-resveratrol, trans-resveratrol, cis-piceid, and trans-piceid in tomato varieties. These compounds were also found in commercial seedless red table grape, with total stilbenoids content of at least 10-fold higher than that in tomato (Table 1; Ragab et al., 2006). Xie and Bolling (2014) reported that California almond (Prunus dulcis) contained piceid, trans-resveratrol, and pterostilbene, however, the level of trans-resveratrol, and pterostilbene were less than the detection limit. Jerkovic et al. (2005) observed trans-piceid $(4.15-8.89 \mathrm{mg} / \mathrm{kg})$, cis-piceid $(2.30-6.01$ $\mathrm{mg} / \mathrm{kg})$, and trans-resveratrol $(0.22-1.00 \mathrm{mg} / \mathrm{kg})$ in 9 hop varieties (Sterling, Wilhamette, Cascade, Nugget, Vanguard, Simcoe, Warrior, Tomahawk, and Amarillo).
Stilbenoids and related compounds are produced by plants for antifungal and antibacterial purposes. Nineteen stilbenoid derivatives were tested in a cellular model system, some of which exhibited antioxidant properties while others were pro-oxidative (Treml et al., 2019). Among these, resveratrol was found to have direct scavenging effect on reactive oxygen species (ROS) (Akinwumi et al., 2018). However, this scavenging effect was relatively low compared to other antioxidants such as ascorbate and cysteine $(\mathrm{Br}-$ adamante et al., 2004; Li et al., 2012).

On a cellular level as a gene regulator, stilbenoids follow multiple mechanisms of action. Stilbenoids-rich Vitis vinifera (grape) stilbenoid derivatives, exhibited antioxidant properties via different mechanisms. First, they were able to stop hydrogen peroxideinduced DNA damage, possibly by up regulation of genes that lead to the activation of antioxidant enzymes which target hydrogen peroxide, such as superoxide dismutase (SOD), catalase and glutathione peroxidases. Second, they activate nuclear factor erythroid 2-related factor-2 (Nrf2) gene and its target genes encoding heme oxygenase-1 (HO-1) and $\gamma$-glutamylcysteine synthetase $(\gamma$-GCS). The up-regulation of these effector molecules directly decreases ROS. Grape root extract also increased in vitro paraoxonase 1 production, which is a high-density lipoprotein (HDL) associated liver protein that prevents low-density lipoprotein (LDL) oxidation (Esatbeyoglu et al., 2016).

Resveratrol is the principle stilbenoid derivative in red wine and is often purified and studied on its own. Its antioxidant effects are assessed in different ways. Resveratrol can bind to around 20 proteins with specific affinity (Britton et al., 2015), leading to the up-regulation of antioxidants and down-regulation of ROS. Among its targets, the activation of NAD+-dependent histone/ protein deacetylase sirtuin 1 (SIRT1), the Nrf2 gene, and estrogen receptors are particularly important. Activation of SIRT1 leads to SIRT1-dependent up-regulation of antioxidant enzymes in human cells and in lab animals in vivo. Activation of the Nrf2 gene leads to Nrf2-dependent up-regulation of antioxidant enzymes, both in cells and in vivo. Binding of resveratrol to estrogen receptors in the cytoplasm leads to the activation of a signaling cascade that regulates the expression of many genes. The end result is both an increase in ROS detoxification and a reduction in ROS production from vascular NADPH oxidases, mitochondria, and uncoupled endothelial nitric oxide synthase (eNOS) (Xia et al., 2017).

\subsection{Anti-inflammatory effect}

Health benefits of stilbenoids are attributed to their antioxidant properties and potent anti-inflammatory effects. In vitro testing of 25 non-prenylated stilbenoids revealed that 5 of them had significant inhibitory effect against cyclooxigenase-1 (COX1) and cycclooxigenase 2 (COX2), which are enzymes that induce inflammation. Among these, trans-resveratrol showed a higher inhibitory roots extract, which contained 7 identifiable naturally occurring 


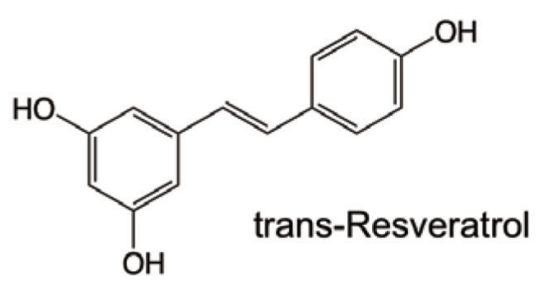<smiles>COc1cc(/C=C/c2ccc(O)cc2)cc(OC)c1</smiles><smiles>Oc1cc(O)cc(/C=C/c2ccc(O)c(O)c2)c1</smiles>

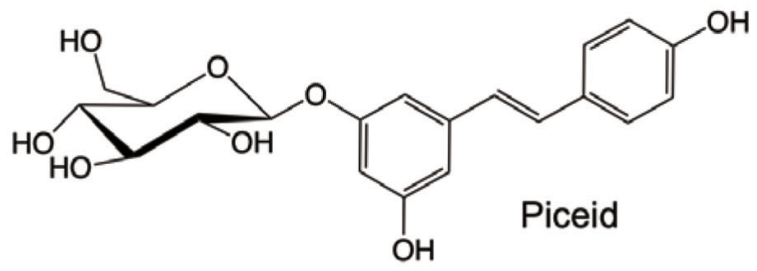<smiles>COc1ccc(/C=C/c2cc(O)cc(O)c2)cc1O</smiles>

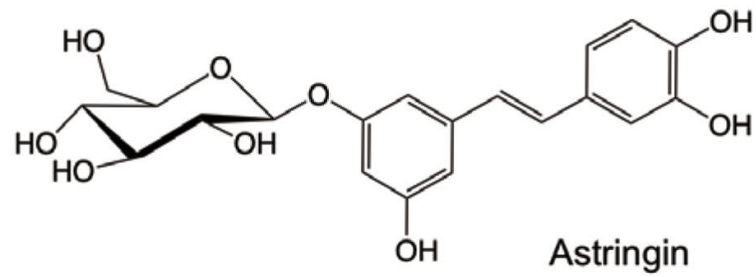

\section{Rhapontigenin}<smiles>Oc1cc(O)cc(/C=C/c2ccccc2)c1</smiles>

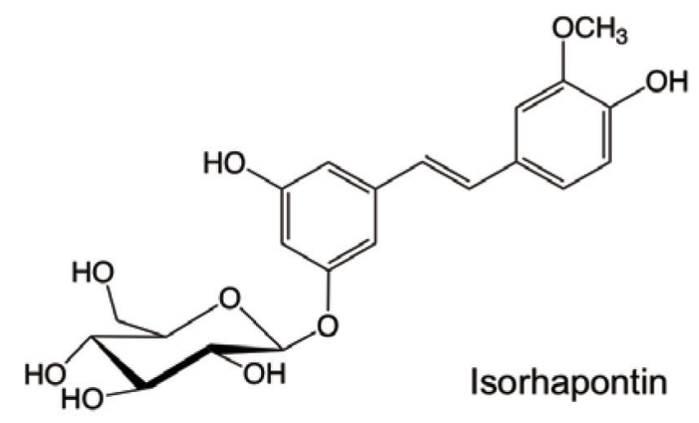<smiles>Oc1ccc([C@H]2c3c(O)cc(O)cc3C3c4cc(O)cc(O)c4[C@@H](c4ccc(O)cc4)C32)cc1</smiles><smiles>Oc1ccc(/C=C/c2cc(O)cc3c2[C@@H](c2cc(O)cc(O)c2)[C@H](c2ccc(O)cc2)O3)cc1</smiles>

Figure 2. Chemical structures of selected stilbenoids.

effect against both $\mathrm{COX} 1$ and $\mathrm{COX} 2$ than ibuprofen, although it was more selective for COX1 than COX2. Pinostilbene showed the greatest selectivity for COX2, even greater than ibuprofen. This is desirable because long-term use of nonsteroidal anti-inflammatory drugs (NSAIDS), which are more selective for COX1, can cause gastrointestinal damage. When considering inhibitory effect against three inflammation enzymes, namely COX1, COX2, and 5-lipoxygenase (5-LOX), piceatannol and pinostilbene showed activities comparable to zileuton and ibuprofen, respectively. Most of the 25 tested stilbenoids showed inhibitory effect against lipopolysaccharide (LPS) stimulated activation of both nuclear factor (NF) $-\mathrm{kB}$ and activator protein (AP)-1 transcription factors. 
<smiles>O=C(O)/C=C/c1ccc(O)cc1</smiles><smiles>O=C(COC(=O)CC(=O)OS)CC(=O)OCc1ccc(O)cc1</smiles>

\section{or}

Claisen reaction Chalcone synthase<smiles>CCCCCCCCCCC(=O)CC(=O)CC(=O)CC(=O)C=Cc1ccc(O)cc1</smiles><smiles>C[C@H]1[C@H](CCCC(=O)CC(=O)S(=O)O)C1(C)C(=O)O</smiles>

\section{CoA ligase}<smiles>CC(C)(C)OC(=O)/C=C/c1ccc(O)cc1</smiles>

p-Coumaroyl-CoA<smiles>O=C(/C=C/c1ccc(O)cc1)c1c(O)cc(O)cc1O</smiles><smiles>O=C(O)c1c(O)cc(O)cc1/C=C/c1ccc(O)cc1</smiles>

Chalcone isomerase

$\mathrm{OH}$<smiles>CC(C)C(=O)O</smiles><smiles>O=C1CC(c2ccc(O)cc2)Oc2cc(O)cc(O)c21</smiles><smiles>Oc1ccc(/C=C/c2cc(O)cc(O)c2)cc1</smiles>

Figure 3. Synthetic pathway of stilbenoid and flavonoid from phenylalanine (Adapted from Shahidi and Naczk, 1995; Roupe et al., 2006a; Vermerris and Nicholson 2008; Dewick, 2002; Shen et al., 2013). PAL denotes phenylalanine ammonia lyase.

Among these, 5 showed comparable effect to prednisone. Reduced transcription of NF- $\mathrm{KB}$ and $\mathrm{AP}-1$ gene attenuated the expression of tumor necrosis factor (TNF)- $\alpha$, which is a powerful pro-inflammatory cytokine. Stilbenoids inhibit NF-kB/AP-1 activity though upstream inhibition of the phosphorylation of mitogen-activated protein kinase (MAPKs) (Leláková et al, 2019).

Prenylated stilbenoids show similar effects in all of the abovementioned mechanisms (Hošek et al, 2019). Theoretically, because of the additional hydrophobic group, prenylated stilbenoids have higher bioavailability and higher distribution rate in the human body than non-prenylated stilbenoids (Araya-Cloutier et al, 2018).

In an experiment that tested 13 stilbenoids and derivatives, natural non-glycosylated stilbenoids were found to down regulate the PI3K/Akt pathway, which is a pathway involved in the regulation of inflammation. The three most potent compounds, piceatannol, pinosylvin, and pterostilbene, were tested in mice with carrageenan-induced paw inflammation. All three stilbenoids suppressed inflammatory edema and down regulated inflammatory mediators interleukin (IL) 6 and monocyte chemoattractant protein (MCP)-1 and their effects were comparable to commercial PI3K inhibitor LY294002 (Eräsalo et al, 2018).

\subsection{Cardiovascular protection}

Due to its antioxidant and anti-inflammatory effects, stilbenoids are tested for their health benefits in a wide range of diseases and conditions. It seems that with the amount of resveratrol level achieved in typical western diet, resveratrol level in the blood is not correlated with protection from all-cause mortality in community dwelling older adult (Semba et al., 2014). For resveratrol to exert any health benefit, supplementation is needed on top of regular diet.

One disease/condition of particular interest is cardiovascular disease (CVD). In a study that tested the effect of resveratrol in the primary prevention of CVD, 75 patients were divided into 


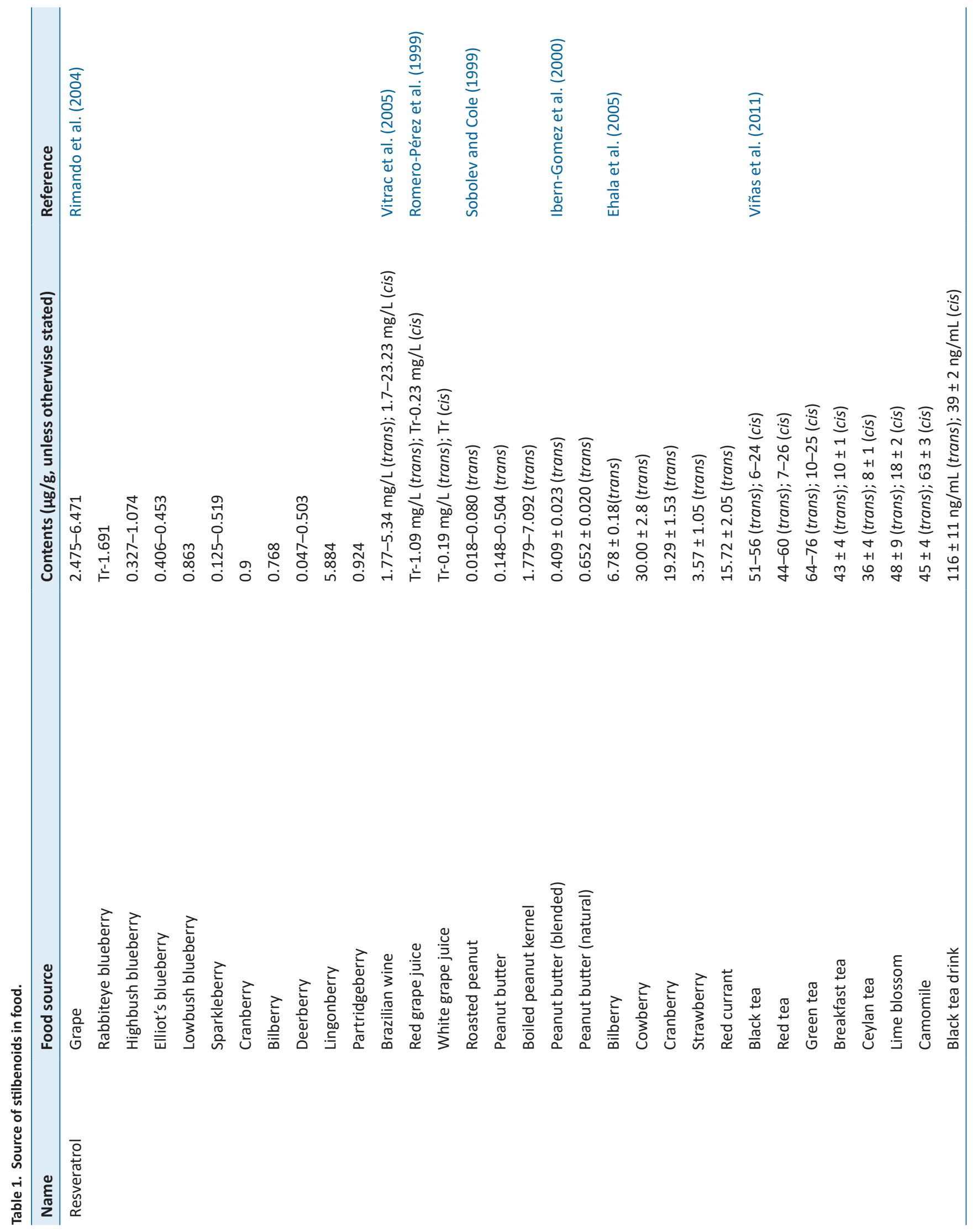




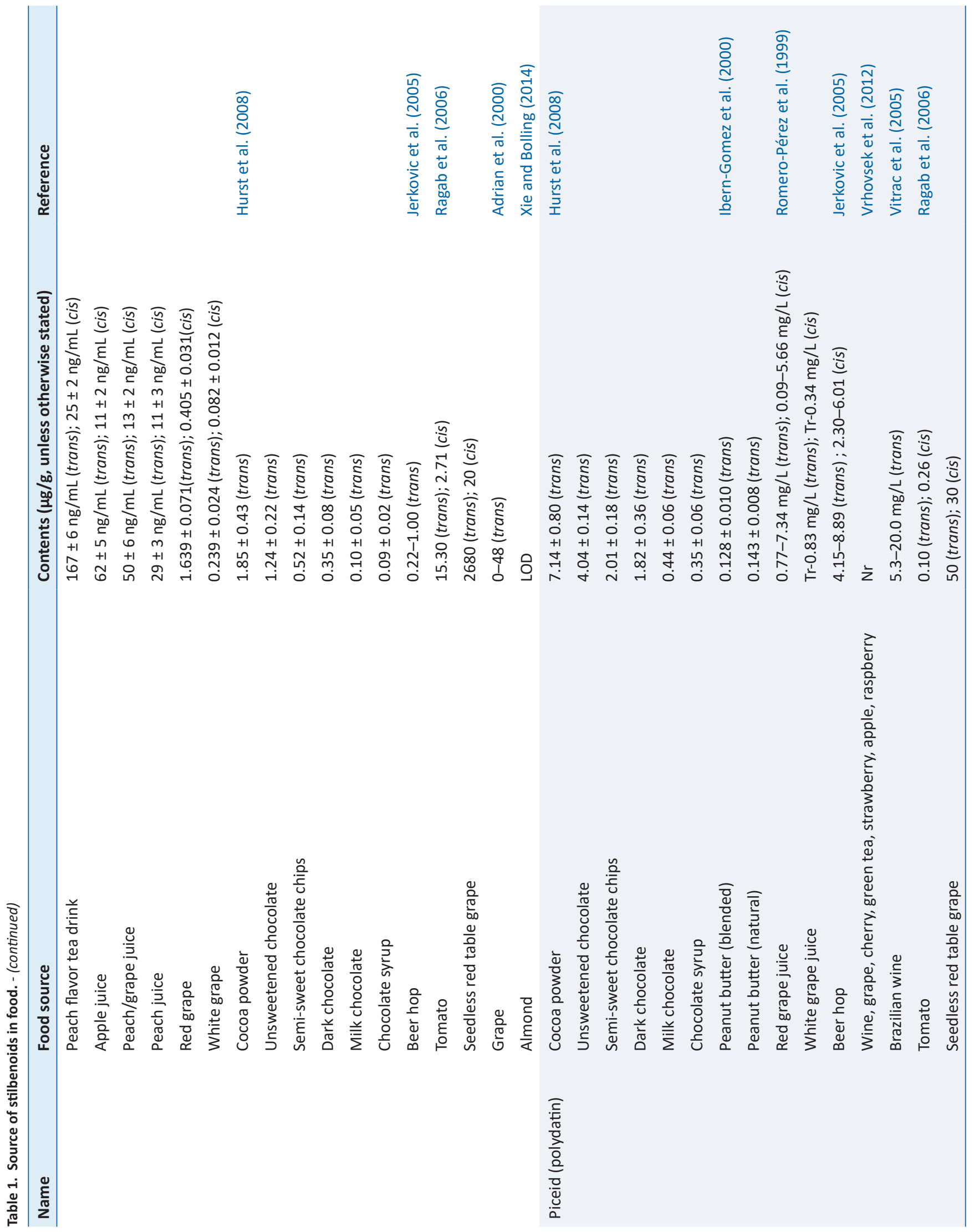



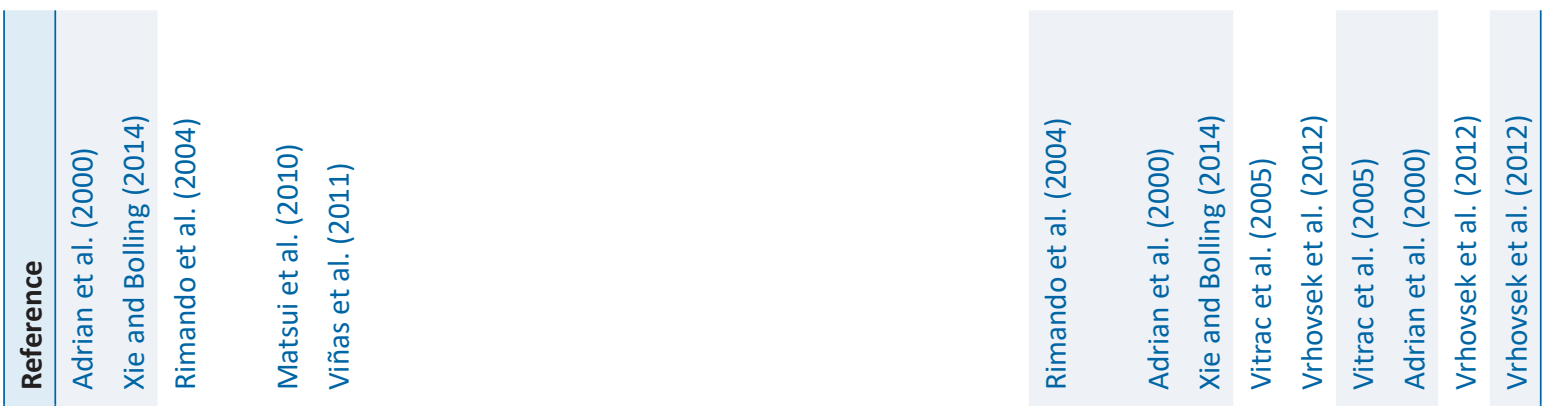

$\sqrt{5}$

-

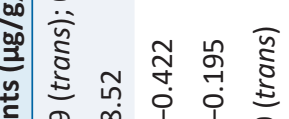

$\vec{\xi} \vec{\xi} \vec{\xi} \vec{\xi} \vec{\xi} \stackrel{0}{0}$ 号

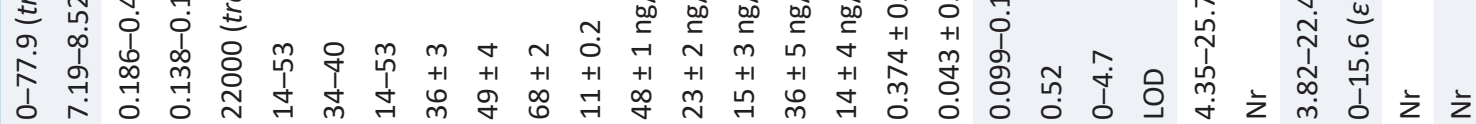

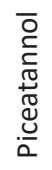


three groups of placebo, resveratrol-rich grape supplement, and conventional grape supplements without resveratrol. These patients were at risk of CVD, but did not yet have cardiovascular event. After a year of consumption, compared to the placebo and supplement without resveratrol, resveratrol-rich grape supplement significantly improved CVD biomarkers in the test group. Improvement in biomarkers such as high-sensitivity $\mathrm{C}$-reactive protein, TNF- $\alpha$, plasminogen activator inhibitor type 1, and IL-6/ IL-10 as well as anti-inflammatory IL-10, signified improved inflammatory and fibrinolytic status in the test group, which is directly correlated to CVD risk. No adverse effect was observed in all patients (Tomé-Carneiro et al., 2012). An interesting study conducted in Spain interviewed 100 participants for their lifestyle, then took blood and urine samples for analysis. In this study, total urinary resveratrol metabolites (TRMs) was used as a biomarker for wine and dietary resveratrol consumption. From analysis of the blood and urine samples, a clear correlation was established that the test subjects with higher TRMs also had lower fasting glucose level, slower heart rate, and better blood lipid profile (lower triacylglycerol and higher high density lipoprotein (HDL)). All these parameters are closely related to CVD, and it can be inferred that resveratrol can decrease the risk of CVD (Zamora-Ros et al., 2012). Another study showed that a 4-week intake of grape pomace extract significantly increased serum resveratrol, and decreased trimethylamine N-oxide (TMAO), another risk factor of CVD (Annunziata et al., 2019).

In overweight patients, effects of resveratrol in improving biomarkers of CVD, as well as anti-inflammatory effects were less pronounced. In patients with schizophrenia, who were generally overweight or obese and had several metabolic disorders, a 4-week supplement of resveratrol $(200 \mathrm{mg} /$ day $)$ did not bring changes to body weight, waist circumference, glucose, and total cholesterol. However, it is worth noting that the blood lipid level (triacylglycerol, HDL) worsened for the control group during the study, but did not change for the test group (Zortea et al., 2016). In another study involving overweight and slightly obese subjects, a 4-week resveratrol supplement $(150 \mathrm{mg} /$ day $)$ did not result in differences in any of the fasting serum or plasma metabolic risk markers such as Apo A-I, Apo B100, HDL, LDL, triacylglycerol, glucose, and insulin. No difference in plasma markers of inflammation or endothelial function was observed (van der Made et al., 2015). In a smaller scale, but well designed, study participants with central obesity were fed high fat meals, which were thought to induce postprandial inflammation. Resveratrol/curcumin supplements were taken before consuming the high fat meal. After the meal, serum samples were taken and analyzed. The supplementation did not make any significant difference in circulating inflammatory markers (C-reactive protein, IL-6, IL-8, MCP-1), adhesion molecules, or whole blood NFKB1 and peroxisome proliferator activated receptor alpha (PPARA) gene expression (Vors et al., 2018). However, this study only tested acute administration of resveratrol/curcumin. Chronic resveratrol intake can potentially give a different result. In a study concerning patients with non-alcoholic fatty liver disease, a 12week supplementation of resveratrol $(500 \mathrm{mg} /$ day $)$ did not result in improvement of waist circumference, insulin resistance biomarkers, lipid profile or blood pressure. However, it improved alanine aminotransferase (ALT) and hepatic steatosis, which are indicators of liver health (Faghihzadeh et al., 2015). In patients with dyslipidemia, a 2-month supplementation of resveratrol (100 mg/day) significantly improved serum concentration of total cholesterol and trigacylglycerol, without significant improvements in HDL or LDL (Simental-Mendía et al., 2019). This study lasted longer than the other previously mentioned studies. Perhaps in overweight or obese patients, it takes a longer duration of supplementation for resveratrol (or other stilbenoids) to show effectiveness on improving CVD biomarkers.

\subsection{Alzheimer's disease}

Stilbenoids can cross the blood brain barrier (BBB) due to their hydrophobic nature. Due to anti-inflammatory effect on organs outside the central nervous system (CNS), stilbenoids may have a similar effect once they cross the BBB. There is also a hypothesis that since mild stressors of caloric restriction (CR) can postpone and prevent diseases of aging in animal models, and because they do so through the activation of sirtuins, then resveratrol as a potent SIRT1 activator, can mimic the physiological effect of CR, thereby postponing the diseases of aging (Pasinetti et al., 2015). The above-mentioned hypothesis led to the testing of resveratrol in Alzheimer's disease (AD).

A 52 weeks long study which supplemented AD patients with 2 grams of synthetic resveratrol daily showed interesting results regarding both the brain conditions and general health. Compared to the placebo group, the test group patients experienced significant weight loss. Nanomolar amounts of native resveratrol were observed in the cerebrospinal fluid (CSF), suggesting the crossing of BBB and binding to molecular targets. Compared to the placebo, resveratrol stabilized the progressive decline in CSF A $\beta 40$ and plasma A $\beta 40$ levels upon advancement of dementia. In individuals with baseline level of CSF A $\beta 42$ less than $600 \mathrm{ng} / \mathrm{mL}$, a confirmation criterion of $\mathrm{AD}$, resveratrol also stabilized CSF A $\beta 42$ level. In the one-year study period, resveratrol attenuated decline in the Alzheimer's Disease Cooperative Study-Activity of Daily Living (ADCS-ADL) score. Because aging is a primary cause of cancer, and resveratrol has anti-aging effect, fewer cases of cancer were found in the resveratrol-treated group ( 1 vs 7 cancer in six participants in the placebo group). Notably, a high dose of resveratrol increased brain volume loss, yet tau protein level remained unaffected (brain volume loss is not due to neuronal loss). This volume loss could be due to the anti-inflammatory effect of resveratrol, which decreases CNS edema in AD brain. Consistent with this hypothesis, pro- and anti-inflammatory biomarkers were significantly better in the CSF and plasma of resveratrol-treated participants (Moussa et al., 2017). Similarly, another study which lasted 52 weeks used $500 \mathrm{mg}$ resveratrol/day, similar but less pronounced results were observed. This suggests that the health benefits of resveratrol are manifested in a dose dependent manner. In this study, decline in CSF A $\beta 40$ and plasma A $\beta 40$ levels, which is a measure of dementia progression, was less in the resveratrol group. There was also a significant weight loss and increased brain volume loss in the treatment group (Turner et al., 2015).

A lower dose of resveratrol, mixed with other nutritional supplements, showed interesting effects on the brain function of healthy elderly individuals. In a 6-month study, healthy elderly participants were supplemented with a combination of $3,000 \mathrm{mg}$ omega-3 PUFAs [1,500 mg docosahexaenoic acid (DHA) and $1,500 \mathrm{mg}$ eicosapentaenoic acid (EPA)], $10 \mu \mathrm{g}$ vitamin D3, 150 $\mathrm{mg}$ resveratrol and $8 \mathrm{~g}$ whey protein isolate. No improvement was observed in their cognitive function test scores. However, the treatment group performed better in the Stroop Color and Word test at the 3- and 6-months follow-up (Moran et al., 2018). Unfortunately, it was impossible to determine how much of that enhanced performance was due to resveratrol. It would be interesting to see if a combination of nutrients, in high doses, could postpone cognitive deterioration in $\mathrm{AD}$ patients.

Raloxifene, a stilbene derivative, works as a selective estrogen receptor modulator. It has beneficial effects in patients with 
ovarian cancer, but does not seem to have any beneficial effect in women with AD. A 52 weeks supplementation of $120 \mathrm{mg}$ of raloxifene daily showed no difference in dementia rating, activities of daily living, behavior, or a global cognition composite score in the treatment group compared to the control group (Henderson et al., 2015).

\subsection{Breast cancer}

Tamoxifen, a stilbene derivative, functions as an estrogen receptor modulator in vivo, and has long-term preventative effect against breast cancer. In a study that tested the long-term effect of tamoxifen, participants who were at high risk of breast cancer received either tamoxifen ( $20 \mathrm{mg}$ daily) or placebo for 5 years. After this 5 -year treatment, participants were followed for 10 years. During this 10 -year follow-up period, there was significantly less breast cancer developed in the treatment group. However, the reduction was mainly in invasive estrogen receptor-positive breast cancer and ductal carcinoma in situ, not so much in invasive estrogen receptor-negative breast cancer (Cuzick et al., 2015). In women who are diagnosed with estrogen receptor (ER)-positive early breast cancer, treatment with tamoxifen for 5 years as an adjuvant substantially reduces the breast cancer mortality rate throughout the first 15 years after diagnosis. If tamoxifen treatment duration was increased to 10 years rather than stopping at 5 years, the mortality rate and recurrence rate were reduced even further, particularly after year 10. The protective effect of tamoxifen was only seen in ER-positive cases, and not in ER-negative type of breast cancer (Davies et al., 2013). This study suggests that low-dose tamoxifen would not affect quality of life (Serrano et al., 2018). However, since tamoxifen is extensively metabolized by liver enzyme CYP2D6, it may cause altered availability of other drugs, and its own availability maybe different in patients who have substantially different CYP2D6 gene profile. Using tamoxifen metabolite transendoxifen, instead of tamoxifen, can bypass the CYP2D6 metabolism. In endocrine-refractory metastatic breast cancer patients, trans-endoxifen provided substantial drug exposure that was unaffected by CYP2D6 metabolism. It also showed acceptable toxicity, and promising antitumor activity (Goetz et al., 2017). Tamoxifen is an effective adjuvant therapy, but it may not be the optimal adjuvant therapy. In postmenopausal women with hormone-receptorpositive early breast cancer who are receiving ovarian suppression, exemestane as an adjuvant seemed to be more effective than tamoxifen (Pagani et al., 2014).

\subsection{Type II diabetes mellitus}

Stilbenoids can improve metabolic syndrome, which leads to protective effect against CVD. Their effect on insulin sensitivity is not only a benefit to metabolic syndrome, but also a protective factor against type II diabetes. A study involving patients with polycystic ovary syndrome found that compared to the control, supplementation with $1,500 \mathrm{mg}$ resveratrol daily for 3 month decreased serum fasting insulin level by $31.8 \%$, and increased Insulin Sensitivity Index by $66.3 \%$ (Banaszewska et al., 2016). Apart from resveratrol, piceatannol from passion fruit extract is also a stilbenoid of interest. Supplementation of piceatannol (20 mg daily) for 8 weeks significantly decreased fasting serum insulin level, improved insulin sensitivity, and also improved blood pressure and heart rate in overweight men. These effects seemed to be less pronounced in overweight female participants, possibly due to the difference in body composition between overweight male and female par- ticipants (Kitada et al., 2017). Piceatannol has also been shown to have protective effect against diabetes in mice models. Although it did not prevent high calorie induced body weight gain or visceral fat gain, it reduced fasting glucose level in obese mice (MarukiUchida et al., 2018). Another study in mice model showed that piceatannol decreased body weight and prevented obesity in a dose dependent manner compared to the control. Piceatannol also improved lipid profile (total cholesterol, LDL, HDL), decreased fasting glucose level, liver weight, spleen weight, as well as perigonadal and retroperitoneal fat. Fatty acid synthesis of liver was reduced, therefore decreasing adipose accumulation in the liver. Piceatannol also significantly altered mice gut microbiota composition compared to the control (Tung et al., 2016).

\subsection{Dry skin}

In vitro studies have shown that passion fruit extract rich in piceatannol can down regulate ROS generation in UVB irradiated human keratinocytes (Maruki-Uchida et al., 2018). It also promotes collagen synthesis and inhibits melanin synthesis in human melanoma and fibroblast cells (Matsui et al., 2010). In women with dry skin, oral supplementation of $5 \mathrm{mg}$ piceatannol daily for 8 weeks significantly increased skin moisture content at week 4 and week 8 compared to the placebo. Transepidermal water loss was also reduced over time. In the end-trial questionnaire, the treatment group also reported a significant reduction in perspiration and fatigue (Maruki-Uchida et al., 2018).

\section{Bioavailability}

\subsection{Resveratrol}

Despite the numerous health benefits of resveratrol, concerns have been expressed due to its bioavailability. Resveratrol was investigated for its absorption, bioavailability, and metabolism in humans; ${ }^{14} \mathrm{C}$-resveratrol was administered orally and intravenously (Walle et al., 2004). Although the highest level of resveratrol and its metabolites in plasma was around $491 \mathrm{ng} / \mathrm{mL}$, unchanged resveratrol was present at less than $5 \mathrm{ng} / \mathrm{mL}$. A rapid decrease of intravenous administration of labeled resveratrol $(0.2 \mathrm{mg})$ was observed due to the distribution, after that it continued to fall during 72-h study period. The recoveries of resveratrol administered orally in the urine and feces were 70.5 and $12.7 \%$, respectively, whereas 64.1 and $10.4 \%$ were recovered in the urine and feces, respectively, in the case of intravenous administration. The authors also found five major metabolites using LC/MS and these were two isomers of resveratrol monoglucuronide, dihydroresveratrol monoglucuronide, resveratrol monosulfate, and dihydroresveratrol sulfate. However, only trace amounts of unchanged resveratrol were identified. They concluded that although the rapid metabolism led to low bioavailability of resveratrol, the metabolites and accumulated resveratrol in epithelial cells and aerodigestive tract might have health benefits (Walle et al., 2004). In addition, resveratrol has extremely low water solubility (less than $0.05 \mathrm{mg} / \mathrm{mL}$ ), which may be another reason for its low bioavailability (Bertacche et al., 2006; Das et al., 2008). There have been many attempts to increase the bioavailability of resveratrol such as increasing its dose (Boocock et al., 2007; Sergides et al., 2016), using cyclodextrin (Das et al., 2008; Silva et al., 2014), solid lipid nanoparticles (Neves et al., 2013), encapsulation (Peñalva et al., 2018), and synthesis of resveratrol derivatives (Sale et al., 2004; Lin and Ho, 2009; Walle, 2011). 


\subsection{Piceatannol}

Piceatannol is a naturally occurring stilbenoid, but is also a metabolite of resveratrol, found in Athymin mice (Niles et al., 2006). The metabolites of piceatannol are piceatannol-diglucuronide, piceatannol monoglucuronide, $O$-methyl piceatannol monoglucuronide, $O$-methyl piceatannol monosulfate, isorhapontigenin, and rhapontigenin in rats after oral administration (Setoguchi et al., 2014). Setoguchi et al. (2014) reported that monoglucuronide metabolite was predominant among the above-mentioned metabolites. They also found that the maximum concentration $\left(\mathrm{C}_{\max }\right)$ of piceatannol was $3.3 \mu \mathrm{mol} / \mathrm{L}$ at $90 \mu \mathrm{mol} / \mathrm{kg}, 7.5 \mu \mathrm{mol} / \mathrm{L}$ at $180 \mu \mathrm{mol} / \mathrm{kg}$, and 8.1 $\mu \mathrm{mol} / \mathrm{L}$ at $360 \mu \mathrm{mol} / \mathrm{kg}$ dose and it reached $\mathrm{C}_{\max } 15 \mathrm{~min}$ after the administration. In addition, the area under the plasma concentration curve (AUC) of piceatannol and its metabolites was increased in a dose-dependent manner. Roupe et al. (2006b) studied the pharmacokinetic characteristics of rhapontigenin, piceatannol and pinosylvin in Sprague-Dawley rats after intravenously administering a single dose of $10 \mathrm{mg} / \mathrm{kg}$. All of test compounds were glucuronidated and AUC of piceatannol, pinosylvin, and rhapontigenin were $8.48 \pm 2.48,5.23 \pm 1.20,8.39 \pm 0.10 \mu \mathrm{g} \mathrm{h} / \mathrm{mL}$, respectively. The total plasma clearance of piceatannol, pinosylvin, and rhapontigenin was $2.130 \pm 0.920,1.840 \pm 0.435$, and $1.180 \pm 0.035 \mathrm{~L} / \mathrm{h} / \mathrm{kg}$, respectively. More information on the bioavailability of piceatannol and its role in metabolic disease is available elsewhere (Kershaw and Kim, 2017). Lin et al. (2010) studied a pre-clinical pharmacokinetics of piceatannol analog (3,5,3',4'-tetramethoxystilbene) in Sprague-Dawley rats using 2-hydroxypropyl- $\beta$-cyclodextrin as a dosing vehicle. They reported that the half-life, clearance, and oral bioavailability of piceatannol analog were $313 \pm 20 \mathrm{~min}, 33.1$ $\pm 3.9 \mathrm{~mL} / \mathrm{min} / \mathrm{kg}$, and $50.7 \pm 15.0 \%$, respectively.

\subsection{Pterostilbene}

Pharmacokinetic study of pterostilbene, a 3,5-dimethyl derivative of resveratrol, was carried out by Lin et al. (2009) in rats. The pterostilbene was administrated intravenously at a dose of $5.0 \mathrm{mg} / \mathrm{kg}$. They reported that the half-life, clearance, and oral bioavailability of pterostilbene were $96.6 \pm 23.7 \mathrm{~min}$ and $37.0 \pm 2.5 \mathrm{~mL} / \mathrm{min} / \mathrm{kg}$, $12.5 \pm 4.7 \%$, respectively, which was better pharmacokinetic characteristics than resveratrol. Kapetanovic et al. (2011) also conducted pharmacokinetics of resveratrol and pterostilbene in rats which were administrated orally via gavage for 14 consecutive days (50 or $150 \mathrm{mg} / \mathrm{kg} /$ day for resveratrol; 56 or $168 \mathrm{mg} / \mathrm{kg} /$ day for pterostilbene). They also prepared two more groups which were administrated once intravenously $(10 \mathrm{mg} / \mathrm{kg}$ resveratrol; $11.2 \mathrm{mg} / \mathrm{kg}$ pterostilbene). The bioavailability of resveratrol and pterostilbene were 20 and $80 \%$, respectively. In addition, the plasma level of pterostilbene and its sulfated metabolites was much higher than that of resveratrol and its sulfated metabolites. On the other hand, the plasma level of resveratrol glucuronide was greater than that of pterostilbene glucuronide, however, the discrepancy of glucuronidated metabolites was smaller compared to the sulfated ones. The authors concluded that pterostilbene had a better pharmacokinetics than resveratrol.

\section{Conclusion}

Stilbenoids show various beneficial effects such as antioxidant, anti-inflammatory, cardioprotective, neuroprotective, anticancer, and anti-diabetes effects. Among these, antioxidant and anti- inflammatory activity of stilbenoids most probably lead to other health promotion and disease prevention effects. However, the results for stilbenoids, especially resveratrol may not necessarily correlate between in vitro and in vivo due to their extensive metabolism. Therefore, in-depth bioavailability study of stilbenoids is needed. Moreover, there have been many attempts to improve poor bioavailability of resveratrol via substitution (methylation, esterification, etc), using different techniques (cyclodextrin, solid lipid nanoparticles, encapsulation). More studies are needed to evaluate the effect of these techniques in vivo. Except for resveratrol, limited information on health effects and bioavailability of stilbenoids is available. Further research is necessary to assess their bioactivity and pharmacokinetic properties.

\section{References}

Adrian, M., Jeandet, P., Douillet-Breuil, A.C., Tesson, L., and Bessis, R. (2000). Stilbene content of mature Vitis vinifera berries in response to UV-C elicitation. J. Agric. Food Chem. 48: 6103-6105.

Akinwumi, B.C., Bordun, K.-A.M., and Anderson, H.D. (2018). Biological activities of stilbenoids. Int. J. Mol. Sci. 19: 792

Annunziata, G., Maisto, M., Schisano, C., Ciampaglia, R., Narciso, V., Tenore, G.C., and Novellino, E. (2019). Effects of grape pomace polyphenolic extract (Taurisolo ${ }^{\circledR}$ ) in reducing TMAO serum levels in humans: Preliminary results from a randomized, placebo-controlled, crossover study. Nutrients. 11: 139.

Araya-Cloutier, C., Vincken, J.P., van Ederen, R., den Besten, H.M.W., and Gruppen, H. (2018). Rapid membrane permeabilization of Listeria monocytogenes and Escherichia coli induced by antibacterial prenylated phenolic compounds from legumes. Food Chem. 240: 147155.

Banaszewska, B., Wrotyńska-Barczyńska, J., Spaczynski, R.Z., Pawelczyk, L., and Duleba, A.J. (2016). Effects of resveratrol on polycystic ovary syndrome: A double-blind, randomized, placebo-controlled trial. J. Clin Endocrinol. Metab. 101: 4322-4328.

Baur, J., and Sinclair, D. (2006). Therapeutic potential of resveratrol: the in vivo evidence. Nat. Rev. Drug Discov. 5: 493-506.

Bertacche, V., Lorenzi, N., Nava, D., Pini, E., and Sinico, C. (2006). Hostguest interaction study of resveratrol with natural and modified cyclodextrins. J. Incl. Phenom. Macrocycl. Chem. 55: 279-287.

Błaszczyk, A., Sady, S., and Sielicka, M. (2019). The stilbene profile in edible berries. Phytochem. Rev. 18: 37-67.

Boocock, D.J., Faust, G.E.S., Patel, K.R., Schinas, A.M., Brown, V.A., Ducharme, M.P., Booth, T.D., Crowell, J.A., Perloff, M., Gescher, A.J., Steward, W.P., and Brenner, D.E. (2007). Phase I dose escalation pharmacokinetic study in healthy volunteers of resveratrol, a potentia cancer chemopreventive agent. Cancer Epidemiol. Biomarkers Prev. 16: 1246-1252.

Bradamante, S., Barenghi, L., and Villa, A. (2004). Cardiovascular protective effects of resveratrol. Cardiovasc. Drug Rev. 22: 169-188.

Britton, R.G., Kovoor, C., and Brown, K. (2015). Direct molecular targets of resveratrol: Identifying key interactions to unlock complex mechanisms. Ann. N. Y. Acad. Sci. 1348: 124-133.

Cuzick, J., Sestak, I., Cawthorn, S., Hamed, H., Holli, K., Howell, A., Forbes, J.F., and on behalf of the IBIS-I investigators. (2015). Tamoxifen for prevention of breast cancer: extended long-term follow-up of the IBIS-I breast cancer prevention trial. Lancet Oncol. 16: 67-75.

Das, S., Lin, H.S., Ho, P.C., and Ng, K.Y. (2008). The impact of aqueous solubility and dose on the pharmacokinetic profiles of resveratrol. Pharm. Res. 25: 2593-2600.

Davies, C., Pan, H., Godwin, J., Gray, R., Arriagada, R., Raina, V., Abraham, M., Alencar, V.H.M., Badran, A., Bonfill, X., Bradbury, J., Clarke, M., Collins, R., Davis, S.R., Delmestri, A., Forbes, J.F., Haddad, P., Hou, M. F., Inbar, M., Khaled, H., Kielanowska, J., Kwan, W.-H., Mathew, B.S. Mittra, I., Müller, B., Nicolucci, A., Peralta, O., Pernas, F., Petruzelka, L., Pienkowski, T., Radhika, R., Rajan, B., Rubach, M.T., Tort, S., Urrútia, G., Valentini, M., Wang, Y., Peto, R., and for the Adjuvant Tamoxifen: Longer Against Shorter (ATLAS) Collaborative Group. (2013). 
Long-term effects of continuing adjuvant tamoxifen to 10 years versus stopping at 5 years after diagnosis of oestrogen receptor-positive breast cancer: ATLAS, a randomised trial. Lancet 381: 805-816.

Dewick, P.M. (2002). Medicinal natural products. A biosynthetic approach. 2nd Edition. Wiley, Chichester, UK, p. 80.

Ehala, S., Vaher, M., and Kaljurand, M. (2005). Characterization of phenolic profiles of Northern European berries by capillary electrophoresis and determination of their antioxidant activity. J. Agric. Food Chem. 53: 6484-6490.

Eräsalo, H., Hämäläinen, M., Leppänen, T., Mäki-Opas, I., Laavola, M., Haavikko, R., Yli-Kauhaluoma, J., and Moilanen, E. (2018). Natural stilbenoids have anti-inflammatory properties in vivo and down-regulate the production of inflammatory mediators NO, IL6, and MCP1 possibly in a PI3K/Akt-dependent manner. J. Nat. Prod. 81: 1131-1142.

Esatbeyoglu, T., Ewald, P., Yasui, Y., Yokokawa, H., Wagner, A.E., Matsugo, S., Winterhalter, P., and Rimbach, G. (2016). Chemical characterization, free radical scavenging, and cellular antioxidant and anti-inflammatory properties of a stilbenoid-rich root extract of Vitis vinifera. Oxid. Med. Cell Longev. 2016: 8591286.

Faghihzadeh, F., Adibi, P., and Hekmatdoost, A. (2015). The effects of resveratrol supplementation on cardiovascular risk factors in patients with non-alcoholic fatty liver disease: A randomised, double-blind, placebo-controlled study. Br. J. Nutr. 114: 796-803.

Goetz, M.P., Suman, V.J., Reid, J.M., Northfelt, D.W., Mahr, M.A., Ralya, A.T., Kuffel, M., Buhrow, S.A., Safgren, S.L., McGovern, R.M., Black, J., Dockter, T., Haddad, T., Erlichman, C., Adjei, A.A., Visscher, D., Chalmers, Z.R., Frampton, G., Kipp, B.R., Liu, M.C., Hawse, J.R., Doroshow, J.H., Collins, J.M., Streicher, H., Ames, M.M., and Ingle, J.N. (2017). First-in-human phase I study of the tamoxifen metabolite Z-endoxifen in women with endocrine-refractory metastatic breast cancer. J. Clin. Oncol. 35: 3391-3400.

Gorham, J. (1980). The stilbenoids. In: Harbome, J.B., Swain, T., and Reinhold, L. (Ed.). Progress in phytochemistry. Pergamon Press, Oxford.

Henderson, V.W., Ala, T., Sainani, K.L., Bernstein, A.L., Stephenson, B.S., Rosen, A.C., and Farlow, M.R. (2015). Raloxifene for women with Alzheimer disease: A randomized controlled pilot trial. Neurology. 85: 1937-1944.

Hošek, J., Leláková, V., Bobál, P., Pížová, H., Gazdová, M., Malaník, M., Jakubczyk, K., Veselý, O., Landa, P., Temml, V., Schuster, D., Prachyawarakorn, V., Pailee, P., Ren, G., Zpurný, F., Oravec, M., and Šmejkal, K. (2019). Prenylated stilbenoids affect inflammation by inhibiting the NF-KB/AP-1 signaling pathway and cyclooxygenases and lipoxygenase. J. Nat. Prod. 82: 1839-1848.

Hurst, W.J., Glinski, J.A., Miller, K.B., Apgar, J., Davey, M.H., and Stuart, D.A. (2008). Survey of the trans-resveratrol and trans-piceid content of cocoa-containing and chocolate products. J. Agric. Food Chem. 56: 8374-8378.

Ibern-Gómez, M., Roig-Pérez, S., Lamuela-Raventós, R., and de la TorreBoronat, M. (2000). Resveratrol and piceid levels in natural and blended peanut butters. J. Agric. Food Chem. 48: 6352-6354.

Jerkovic, V., Callemien, D., and Collin, S. (2005). Determination of stilbenes in hop pellets from different cultivars. J. Agric. Food Chem. 53: 4202-4206.

Kapetanovic, I.M., Muzzio, M., Huang, Z., Thompson, T.N., and McCormick, D.L. (2011). Pharmacokinetics, oral bioavailability, and metabolic profile of resveratrol and its dimethylether analog, pterostilbene, in rats. Cancer Chemother. Pharmacol. 68: 593-601.

Kershaw, J., and Kim, K.-H. (2017). The therapeutic potential of piceatannol, a natural stilbene, in metabolic diseases: A review. J. Med. Food 20: 427-438.

Kitada, M., Ogura, Y., Maruki-Uchida, H., Sai, M., Suzuki, T., Kanasaki, K., Hara, Y., Seto, H., Kuroshima, Y., Monno, I., and Koya, D. (2017). The effect of piceatannol from passion fruit (Passiflora edulis) seeds on metabolic health in humans. Nutrients 9: 1142.

Kuć, J. (1995). Phytoalexins, stress metabolism, and disease resistance in plants. Annu. Rev. Phytopathol. 33: 275-297.

Langcake, P., and Pryce, R.J. (1977). A new class of phytoalexins from grapevines. Experientia 33: 151-152.

Leláková, V., Šmejkal, K., Jakubczyk, K., Veselý, O., Landa, P., Václavík, J., Bobál', P., Pížová, H., Temml, V., Steinacher, T., Schuster, D., Granica, S., Hanáková, Z., and Hošek, J. (2019). Parallel in vitro and in silico investigations into anti-inflammatory effects of non-prenylated stilbenoids. Food Chem. 285: 431-440.

Li, H., Xia, N., and Forstermann, U. (2012). Cardiovascular effects and molecular targets of resveratrol. Nitric Oxide 26: 102-110.

Lin, H.-S., and Ho, P.C. (2009). A rapid HPLC method for the quantification of 3,5,4-trimethoxy-trans-stilbene (TMS) in rat plasma and its application in pharmacokinetic study. J. Pharm. Biomed. Anal. 49: 387-392.

Lin, H.-S., Tringali, C., Spatafora, C., Wu, C., and Ho, P.C. (2010). A simple and sensitive HPLC-UV method for the quantification of piceatannol analog trans-3,5,3', $4^{\prime}$-tetramethoxystilbene in rat plasma and its application for a pre-clinical pharmacokinetic study. J. Pharm. Biomed. Anal. 51: 679-684.

Lin, H.-S., Yue, B.-D., and Ho, P.C. (2009). Determination of pterostilbene in rat plasma by a simple HPLC-UV method and its application in preclinical pharmacokinetic study. Biomed. Chromatogr. 23: 1308-1315.

Maruki-Uchida, H., Morita, M., Yonei, Y., and Sai, M. (2018). Effect of passion fruit seed extract rich in piceatannol on the skin of women: $A$ randomized, placebo-controlled, double-blind trial. J. Nutr. Sci. Vitaminol. (Tokyo) 64: 75-80.

Matsui, Y., Sugiyama, K., Kamei, M., Takahashi, T., Suzuki, T., Katagata, Y., and Ito, T. (2010). Extract of passion fruit (Passiflora edulis) seed containing high amounts of piceatannol inhibits melanogenesis and promotes collagen synthesis. J. Agric. Food Chem. 58: 11112-11118.

Moran, C., di Palumbo, A.S., Bramham, J., Moran, A., Rooney, B., De Vito G., and Egan, B. (2018). Effects of a six-month multi-ingredient nutrition supplement intervention of omega-3 polyunsaturated fatty acids, vitamin $D$, resveratrol, and whey protein on cognitive function in older adults: A randomised, double-blind, controlled trial. J. Prev. Alzheimers Dis. 5: 175-183.

Moussa, C., Hebron, M., Huang, X., Ahn, J., Rissman, R.A., Aisen, P.S., and Turner, R.S. (2017). Resveratrol regulates neuro-inflammation and induces adaptive immunity in Alzheimer's disease. J. Neuroinflammation 14: 1 .

Neves, A.R., Lúcio, M., Martins, S., Lima, J.L., and Reis, S. (2013). Novel resveratrol nanodelivery systems based on lipid nanoparticles to enhance its oral bioavailability. Int. J. Nanomed. 8: 177-187.

Niles, R.M., Cook, C.P., Meadows, G.G., Fu, Y.M., McLaughlin, J.L., and Rankin, G.O. (2006). Resveratrol is rapidly metabolized in athymic $(\mathrm{Nu} / \mathrm{Nu})$ mice and does not inhibit human melanoma xenograft tumor growth. J. Nutr. 136: 2542-2546.

Oh, W.Y., and Shahidi, F. (2017). Lipophilization of resveratrol and effects on antioxidant activities. J. Agric. Food Chem. 65: 8617-8625.

Oh, W.Y., Chiou, Y.-.S., Pan, M.-.H., and Shahidi, F. (2019). Lipophilised resveratrol affects generation of reactive nitrogen species in murine macrophages and cell viability of human cancer cell lines. J. Food Bioactives 7: 73-77.

Pagani, O., Regan, M.M., Walley, B.A., Fleming, G.F., Colleoni, M., Láng, I., Gomez, H.L., Tondini, C., Burstein, H.J., Perez, E.A., Ciruelos, E., Stearns, V., Bonnefoi, H.R., Martino, S., Geyer Jr, C.E., Pinotti, G., Puglisi, F., Crivellari, D., Ruhstaller, T., Winer, E.P., Rabaglio-Poretti, M., Maibach, R., Ruepp, B., Giobbie-Hurder, A., Price, K.N., Bernhard, J., Luo, W., Ribi, K., Viale, G., Coates, A.S., Gelber, R.D., Goldhirsch, A. Francis, P.A., and for the TEXT and SOFT Investigators and the International Breast Cancer Study Group. (2014). Adjuvant exemestane with ovarian suppression in premenopausal breast cancer. N. Engl. J. Med. 371: 107-118.

Pasinetti, G.M., Wang, J., Ho, L., Zhao, W., and Dubner, L. (2015). Roles of resveratrol and other grape-derived polyphenols in Alzheimer's disease prevention and treatment. Biochim. Biophys. Acta. 1852: 1202-1208.

Peñalva, R., Morales, J., González-Navarro, C.J., Larrañeta, E., Quincoces, G., Peñuelas, I., and Irache, J.M. (2018). Increased oral bioavailability of resveratrol by its encapsulation in casein nanoparticles. Int. J. Mol. Sci. 19: 2816.

Ragab, A.S., Van Fleet, J., Jankowski, B., Park, J.-H., and Bobzin, S.C. (2006) Detection and quantitation of resveratrol in tomato fruit (Lycopersicon esculentum Mill.). J. Agric. Food Chem. 54: 7175-7179.

Rimando, A.M., Kalt, W., Magee, J.B., Dewey, J., and Ballington, J.R. (2004). Resveratrol pterostilbene, and piceatannol in vaccinium berries. J. Agric. Food Chem. 52: 4713-4719. 
Romero-Pérez, A., Ibern-Gómez, M., Lamuela-Raventós, R., and de la Torre-Boronat, M. (1999). Piceid, the major resveratrol derivative in grape juices. J. Agric. Food Chem. 47: 1533-1536.

Roupe, K.A., Remsberg, C.M., Yañez, J.A., and Davies, N.M. (2006a). Pharmacometrics of stilbenes: Seguing towards the clinic. Current Clin. Pharm. 1: 81-101.

Roupe, K.A., Yáñez, J.A., Teng, X.W., and Davies, N.M. (2006b). Pharmacokinetics of selected stilbenes: rhapontigenin, piceatannol and pinosylvin in rats. J. Pharm. Pharmacol. 58: 1443-1450.

Sale, S., Verschoyle, R.D., Boocock, D., Jones, D.J.L., Wilsher, N., Ruparelia, K.C., Potter, G.A., Farmer, P.B., Steward, W.P., and Gescher, A.J. (2004). Pharmacokinetics in mice and growth-inhibitory properties of the putative cancer chemopreventive agent resveratrol and the synthetic analoguetrans 3,4,5,4-tetramethoxystilbene. Br. J. Cancer 90: 736-744.

Semba, R.D., Ferrucci, L., Bartali, B., Urpí-Sarda, M., Zamora-Ros, R., Sun, K., Cherubini, A., Bandinelli, S., and Andres-Lacueva, C. (2014). Resveratrol levels and all-cause mortality in older community-dwelling adults. JAMA Intern Med. 174: 1077-1084.

Sergides, C., Chirilă, M., Silvestro, L., Pitta, D., and Pittas, A. (2016). Bioavailability and safety study of resveratrol $500 \mathrm{mg}$ tablets in healthy male and female volunteers. Exp. Ther. Med. 11: 164-170.

Serrano, D., Gandini, S., Guerrieri-Gonzaga, A., Feroce, I., Johansson, H., Macis, D., Aristarco, V., Bonanni, B., and DeCensi, A. (2018). Quality of life in a randomized breast cancer prevention trial of low-dose tamoxifen and fenretinide in premenopausal women. Cancer Prev. Res. 11: 811-818.

Setoguchi, Y., Oritani, Y., Ito, R., Inagaki, H., Maruki-Uchida, H., Ichiyanagi, T., and Ito, T. (2014). Absorption and metabolism of piceatannol in rats. J. Agric. Food Chem. 62: 2541-2548.

Shahidi, F., and Naczk, M. (1995). Phenolics in food and nutraceuticals. CRC press, Boca Raton, Florida, pp. 4-5.

Shen, T., Xie, C.-F., Wang, X.-N., and Lou, H.-X. (2013). Stilbenoids. In: Ramawat, K.G., and Mérillon, J.M. (Ed.). Natural Products. SpringerVerlag, Berlin, Heidelberg, pp. 1901-1949.

Silva, F., Figueiras, A., Gallardo, E., Nerín, C., and Domingues, F.C. (2014). Strategies to improve the solubility and stability of stilbene antioxidants: A comparative study between cyclodextrins and bile acids. Food Chem. 145: 115-125.

Simental-Mendía, L.E., and Guerrero-Romero, F. (2019). Effect of resveratrol supplementation on lipid profile in subjects with dyslipidemia: A randomized double-blind, placebo-controlled trial. Nutrition 58: 7-10.

Sobolev, V.S., and Cole, R.J. (1999). trans-Resveratrol content in commercial peanuts and peanut products. J. Agric. Food Chem. 47: 14351439.

Soleas, G.J., Diamandis, E.P., and Goldberg, D.M. (1997). Resveratrol: A molecule whose time has come? And gone? Clin. Biochem. 30: 91113.

Tomé-Carneiro, J., Gonzálvez, M., Larrosa, M., Yáñez-Gascón, M.J., GarcíaAlmagro, F.J., Ruiz-Ros, J.A., García-Conesa, M.T., Tomás-Barberán, F.A., and Espín, J.C. (2012). One-year consumption of a grape nutraceutical containing resveratrol improves the inflammatory and fibrinolytic status of patients in primary prevention of cardiovascular disease. Am. J. Cardiol. 110: 356-363.

Treml, J., Leláková, V., Šmejkal, K., Paulíčková, T., Labuda, Š., Granica, S., Havlík, J., Jankovská, D., Padrtová, T., and Hošek, J. (2019). Antioxidant activity of selected stilbenoid derivatives in a cellular model system. Biomolecules 9: 468

Tung, Y.-C., Lin, Y.-H., Chen, H.-J., Chou, S.-C., Cheng, A.-C., Kalyanam, N., Ho, C.-T., and Pan, M.-H. (2016). Piceatannol exerts anti-obesity effects in C57BL/ 6 mice through modulating adipogenic proteins and gut microbiota. Molecules 21: 1419.

Turner, R.S., Thomas, R.G., Craft, S., van Dyck, C.H., Mintzer, J., Reynolds, B.A., Brewer, J.B., Rissman, R.A., Raman, R., Aisen, P.S., and for the Alzheimer's disease cooperative study. (2015). A randomized, double-blind, placebo-controlled trial of resveratrol for Alzheimer disease. Neurology 85: 1383-1391.

van der Made, S.M., Plat, J., and Mensink, R.P. (2015). Resveratrol does not influence metabolic risk markers related to cardiovascular health in overweight and slightly obese subjects: a randomized, placebocontrolled crossover trial. PLoS One 10: e011839.

Vermerris, W., and Nicholson, R. (2008). Phenolic compound biochemistry. Springer, The Netherland, p. 130.

Viñas, P., Martínez-Castillo, N., Campillo, N., and Hernández-Córdoba, M. (2011). Directly suspended droplet microextraction with in injectionport derivatization coupled to gas chromatography-mass spectrometry for the analysis of polyphenols in herbal infusions, fruits and functional foods. J. Chromatogr. A 1218: 639-646.

Vitrac, X., Bornet, A., Vanderlinde, R., Valls, J., Richard, T., Delaunay, J., Mérillon, J., and Teissédre, P. (2005). Determination of stilbenes $(\delta$-viniferin, trans-astringen, trans-piceid, cis- and trans-resveratrol, $\varepsilon$-viniferin) in Brazilian wines. J. Agric. Food Chem. 53: 5664-5669.

Vors, C., Couillard, C., Paradis, M.E., Gigleux, I., Marin, J., Vohl, M.-C., Couture, P., and Lamarche, B. (2018). Supplementation with resveratro and curcumin does not affect the inflammatory response to a highfat meal in older adults with abdominal obesity: A randomized, placebo-controlled crossover trial. J. Nutr. 148: 379-388.

Vrhovsek, U., Masuero, D., Gasperotti, M., Franceschi, P., Caputi, L., Viola, R., and Mattivi, F. (2012). A versatile targeted metabolomics method for the rapid quantification of multiple classes of phenolics in fruits and beverages. J. Agric. Food Chem. 60: 8831-8840.

Walle, T. (2011). Bioavailability of resveratrol. Ann. N.Y. Acad. Sci. 1215: 9-15.

Walle, T., Hsieh, F., DeLegge, M.H., Oatis, Jr, J.E., and Walle, U.K. (2004). High absorption but very low bioavailability of oral resveratrol in humans. Drug Metab. Dispos. 32: 1377-1382.

Xia, N., Daiber, A., Förstermann, U., and Li, H. (2017). Antioxidant effects of resveratrol in the cardiovascular system. Br. J. Pharmacol. 174 1633-1646.

Xiao, K., Zhang, H.-J., Xuan, L.-J., Zhang, J., Xu, Y.-M., and Bai, D.-L. (2008). Stilbenoids: Chemistry and bioactivities. In: Atta-ur-Rahman (Ed.). Studies in Natural Products Chemistry, Vol. 34. Elsevier, Amsterdam, pp. 453-646.

Xie, L., and Bolling, B.W. (2014). Characterisation of stilbenes in California almonds (Prunus dulcis) by UHPLC-MS. Food Chem. 148: 300-306.

Zamora-Ros, R., Urpi-Sarda, M., Lamuela-Raventós, R.M., MartínezGonzález, M.Á., Salas-Salvadó, J., Arós, F., Fitó, M., Lapetra, J., Estruch, R., Andres-Lacuevaa, C., and on behalf of the PREDIMED study investigators. (2012). High urinary levels of resveratrol metabolites are associated with a reduction in the prevalence of cardiovascular risk factors in high-risk patients. Pharmacol. Res. 65: 615-620.

Zortea, K., Franco, V.C., Francesconi, L.P., Cereser, K.M., Lobato, M.I., and Belmonte-de-Abreu, P.S. (2016). Resveratrol supplementation in Schizophrenia patients: A randomized clinical trial evaluating serum glucose and cardiovascular risk factors. Nutrients 8: 73. 